\title{
O Banco Mundial e a educação superior brasileira na primeira década do novo século
}

\author{
Kátia Regina de Souza Lima \\ Universidade Federal Fluminense (UFF)
}

\section{O Banco Mundial e a educação superior brasileira na primeira década do novo século}

Resumo: O artigo analisa as políticas promovidas pelo Banco Mundial para a educação superior dos países periféricos nos anos 1990 e na primeira década do novo século. Considera que as diretrizes centrais destas políticas (diversificação das instituições de ensino superior, dos cursos e das fontes de financiamento) foram implementadas no Brasil pelo governo Luís Inácio Lula da Silva através do empresariamento da educação superior, das parcerias público-privadas na educação superior e dos contratos de gestão. Este processo resultou na desconstrução da educação pública brasileira como um direito social e na estruturação de um tipo de universidade adequada a atual etapa de acumulação do capital, particularmente em um país capitalista dependente como o Brasil.

Palavras-chave: Organismos internacionais. Educação superior. Universidades brasileiras.

\section{The World Bank and Brazilian Higher Education in the First Decade of the New Century}

Abstract: This article analyzes higher education policies promoted by the World Bank in peripheral countries in the 1990s and the first decade of the new century. It found that the central guidelines of these policies (diversification of institutions of higher education, schools and financing sources) were implemented in Brazil by the government of President Luís Inácio Lula da Silva. Higher education has been treated as a business and placed in the hands of public-private partnerships in higher education through management contracts. This process has led to the deconstruction of Brazilian public education as a social right and to the formation of a type of university suitable to the current phase of capital accumulation, particularly in a dependent capitalist country such as Brazil.

Key words: International agencies. Higher education. Brazilian universities. 


\section{Introdução}

$\mathrm{O}$ presente artigo tem como objetivo analisar as políticas promovidas pelo Banco Mundial (BM) e como estas políticas interferiram na educação superior brasileira da metade da década de 1990 a primeira década do novo século. Neste período, os governos Fernando Henrique Cardoso e Luiz Inácio Lula da Silva, em absoluta consonância com as políticas do BM, operaram um conjunto de reformulações na política de educação superior a partir de dois eixos centrais: a diversificação das instituições de ensino superior (IES) e dos cursos e a diversificação das suas fontes de financiamento ${ }^{1}$.

No primeiro item, analisaremos quatro dos principais documentos elaborados pelo BM neste período, buscando apreender as diretrizes da reformulação do Estado e da educação superior difundidas para os países periféricos ${ }^{2}$, especialmente o deslocamento efetuado pelo Banco: da concepção de "educação superior" para "educação terciária".

A seguir, no item dois, apresentaremos as principais ações conduzidas pelo governo Lula da Silva, demonstrando que essas ações estavam em conformidade com a política do BM para a "educação terciária", particularmente no que se refere: a) ao estímulo ao empresariamento da educação superior; b) à ampliação da privatização interna das universidades públicas e c) ao estabelecimento de contratos de gestão que alteram o financiamento e as diretrizes político-pedagógicas das universidades públicas, especialmente das universidades federais.

$\mathrm{O}$ artigo indica, por fim, como este intenso processo de reformulação da educação superior brasileira efetiva a desconstrução da educação pública brasileira como um direito social. $\mathrm{O}$ direito à educação é reconfigurado por meio da privatização em larga escala; do repasse (direto e indireto) dos recursos públicos ao setor privado, além de adoção da lógica empresarial como modelo de gestão nas instituições educacionais públicas, privilegiando a relação custo-benefício, a eficácia e a qualidade medidas pela relação com o mercado; de que são importantes referências, a certificação e a fragmentação do ensino e dos conhecimentos; o aligeiramento da formação profissional e a intensificação do trabalho docente. Um processo de reformulação que configurou a educação como um campo de exploração lucrativa para o capital em crise e aprofundou sua função política, econômica e ideo-cultural de reprodução da concepção burguesa de mundo.

\section{O Banco Mundial e a educação superior na década de 1990 e no início do novo século}

Ao longo da década de 1990, desencadeou-se uma ampliação do espaço privado nas atividades direta- mente ligadas à produção econômica e também no campo dos direitos sociais, conquistados pelas lutas históricas da classe trabalhadora, o que gerou um aprofundamento da mercantilização da educação, particularmente da educação superior. Essa ampliação foi realizada através de dois movimentos: a) a expansão das instituições privadas, através da liberalização dos "serviços educacionais"; b) a privatização interna das universidades públicas, através das fundações de direito privado, das cobranças de taxas e mensalidades pelos cursos pagos e do estabelecimento de parcerias entre as universidades públicas e as empresas, redirecionando as atividades de ensino, pesquisa e extensão.

Estes dois elementos estavam presentes no documento La enseñanza superior - las lecciones derivadas de la experiencia, publicado em 1994 pelo BM no qual foram apresentadas quatro estratégias para a reforma da educação superior na América Latina, Ásia e Caribe. A primeira previa a diversificação das instituições de ensino superior e dos cursos, sob o pressuposto da necessidade de existência de universidades públicas, privadas e de instituições não universitárias, incluindo os cursos politécnicos, os cursos de curta duração, os ciclos e o ensino a distância.

A diversificação das fontes de financiamento das universidades públicas apresentou-se como a segunda estratégia. Para tanto, o BM defendeu a necessidade de cobrança de matrículas e mensalidades para os estudantes; o corte de verbas públicas para as atividades consideradas "não relacionadas com a educação" (alojamento/moradia estudantil e alimentação/bandejão); assim como a utilização de verbas privadas advindas de doações de empresas e das associações dos ex-alunos, dos cursos de curta duração, dos cursos pagos e da venda de "serviços educacionais", como consultorias e pesquisas. Esses "serviços" deveriam ser administrados através de convênios firmados entre as universidades públicas e as empresas, mediados pelas fundações de direito privado, concebidas como estruturas administrativamente mais flexíveis (BANCO MUNDIAL, 1994).

A terceira estratégia definiu as funções do Estado no sentido de construir um novo arcabouço político e jurídico que viabilizasse a implantação das diretrizes privatizantes da educação. Por fim, a quarta estratégia, implantação de uma política de "qualificação" do ensino superior era concebida a partir do eficiente atendimento aos setores privados:

Las instituciones a cargo de los programas avanzados de enseñanza e investigación deberían contar con la orientación de representantes de los sectores productivos. La participación de los representantes del sector privado en los consejos de administración de las instituciones de enseñanza superior, públicas y privadas, puede contribuir a 
asegurar la pertinencia de los programas académicos (BANCO MUNDIAL, 1994, p. 79).

Em 1997, o BM lançou um importante documento que tratava, especificamente, da reformulação do papel do Estado nos países periféricos. Diferente da concepção presente nos documentos datados do início da década de 1990, o BM elaborou um conjunto de reflexões em relação ao fenômeno que identificava como um "distanciamento entre o Estado e o povo", gerado pela lógica do Estado mínimo e do mercado como gestor da vida social, iniciando um processo de difusão de um conjunto de noções que reivindicavam a construção de um "estado mais próximo do povo", um "estado em um mundo em transformação", temática específica do Relatório sobre o Desenvolvimento Mundial elaborado pelo BM em 1997.

O núcleo central do Relatório de 1997 se referia à defesa de que "o Estado é fundamental para o processo de desenvolvimento econômico e social, porém não enquanto agente direto do crescimento, mas sim como um sócio, elemento catalisador e impulsionador deste processo" (BANCO MUNDIAL, 1997, p. 2). Criticando o monopólio estatal dos serviços de infraestrutura e dos serviços sociais, o BM defendeu o papel do Estado: a) em ações que promovam a segurança pública (do combate à violência às parcerias com os empresários e trabalhadores no financiamento do sistema de seguridade social); b) na elaboração de uma regulamentação eficaz que aproveite as "forças do mercado" em benefício dos "bens públicos", estimulando as parcerias público-privadas; c) no incentivo à política industrial, inclusive com subvenções para o setor privado; d) na gestão eficaz da privatização das empresas estatais; e) no estímulo a maior "competência" no interior da administração pública, através de um sistema de contratação por mérito e de avaliação por produtividade e f) na formulação de políticas que viabilizassem a participação dos empresários, dos sindicatos e dos usuários na supervisão dos serviços da administração pública (BANCO MUNDIAL, 1997).

O reordenamento do papel do Estado, eixo norteador da política do BM para a periferia do capitalismo, consolidou, ao longo da década de 1990 e no início do novo século, um intenso processo de privatização dos serviços públicos, incluindo a educação e, especialmente, a educação superior.

Em 1999, o BM lança outro documento Estratégia para o setor educacional - documento estratégico do Banco Mundial: a educação na América Latina e Caribe contendo avaliações quanto à educação na região durante a década de 1990 e as diretrizes a serem implementadas no século 21 . Novamente, o BM reforçou o papel da educação como estratégia de "alívio à pobreza"3 articulado à ampliação do setor privado neste nível de ensino. O centro desta política estava expresso na segurança do capital para atravessar, conquistar e submeter países e regiões a mundialização financeira (CHESNAIS, 1999); na atualização da força de trabalho para responder às novas demandas da divisão internacional do trabalho e no aprofundamento da privatização de setores estratégicos dos países periféricos, como energia, telecomunicações e educação.

Nos últimos anos, elementos de continuidade e novas expressões vêm à tona no que tange a abertura do "setor educacional” como opção de investimentos de grupos privados. O elemento de continuidade é garantido pelo reforço à concepção de educação como instrumento de preparação da força de trabalho para o mercado e também de dominação ideológica através da visão burguesa de mundo. $\mathrm{O}$ elemento de novidade é o crescente empresariamento da educação (NEVES, 2002), operado pelo BM em articulação com a Organização Mundial do Comércio (OMC) a partir de três aspectos importantes.

O primeiro diz respeito à "globalização" crescente dos sistemas educacionais na América Latina; sendo cada vez mais significativos, na região, os incentivos para que universidades públicas e privadas associem-se às universidades/instituições dos países centrais. Essa "globalização" dos sistemas educacionais ocorre via formação de parcerias entre empresas educacionais com sede nos Estados Unidos e Europa, além de polos espalhados por várias regiões de interesse do capital. Estas parcerias viabilizam a venda de modelos pedagógicos, a comercialização de programas de ensino e de livros didáticos, especialmente para a formação e treinamento de professores em serviço, objetivando a consolidação de um caldo ideológico e político que legitime e reproduza a lógica hegemônica 4 . 
O segundo refere-se à constituição das universidades corporativas implementadas pelas empresas para formação e (re)qualificação dos trabalhadores, em seus locais de trabalho e com um conhecimento dirigido para os seus interesses imediatos.

O terceiro se expressa no incentivo ao investimento no ensino a distância, impulsionado pelas inovações tecnológicas, através da venda de pacotes tecnológicos e/ou implantação de universidades virtuais, parceiras de universidades estadunidenses e europeias. Neste projeto, estão articuladas as empresas dos países centrais, principalmente a IBM, a Microsoft e as empresas da mídia, como Time Warner e os organismos internacionais.

Uma importante referência desta intensificação da mercantilização da educação superior no início do novo século está expressa no documento do BM intitulado Construir sociedades de conocimiento: nuevos desafíos para la educación terciaria, publicado em 2002. Este documento operou um importante deslocamento da concepção de "educação superior" para "educação terciária". Esse deslocamento estava inscrito na concepção do BM de que estamos na "sociedade do conhecimento", na medida em que este se constituiu como fator primário da produção na economia mundi$\mathrm{al}^{5}$. Neste sentido, o BM reivindicou o aprofundamento da diversificação das instituições de ensino superior e dos cursos e das fontes de financiamento, considerando que os governos dos países periféricos

Incrementen la diversificación institucional (aumento del número de instituciones no universitarias y privadas) para ampliar la cobertura sobre una base financiera viable y para establecer un marco de formación continua con múltiples puntos de acceso y gran variedad de itinerarios formativos (BANCO MUNDIAL, 2002, p. 27).

Este deslocamento evidenciou que a diversificação, eixo norteador das políticas do BM ao longo da década de 1990, ganhou nova racionalidade, na medida em que qualquer curso "pós-médio" (público ou privado) era considerado de nível "terciário", seja através da emissão de diplomas, certificados ou atestados de aproveitamento.

En los pasados dos decenios, muchos países han experimentado una extraordinaria diversificación en sus sectores de educación terciaria. La aparición de diversas instituciones nuevas paralelas a las universidades tradicionales - 'institutos técnicos para estudios de corta duración, community colleges, politécnicos, centros de educación terciaria popular con programas bienales, centros de enseñanza a distancia y universidades abiertas' - ha creado nuevas oportunidades para satisfacer la demanda social creciente. En América Latina, Asia y, más recientemente, en Europa Oriental y África subsahariana, esta tendencia se ha visto intensificada por el 'rápido crecimiento en el número y tamaño de las instituciones privadas de educación terciária' (BANCO MUNDIAL, 2002, p. 69, grifos nossos).

Nos marcos do "alargamento/intensificação" da política de diversificação das IES e dos cursos e das fontes de financiamento da educação superior, operada pela concepção de "educação terciária", defendida e difundida pelo BM, é que será implementada,no Brasil, uma intensa reformulação da educação superior.

\section{A Reformulação da educação superior bra- sileira na primeira década do novo século}

Essa intensa reformulação da educação superior em nosso país ocorre a partir de um conjunto de leis, decretos e medidas provisórias ${ }^{6}$, como:

a) o Sistema Nacional de Avaliação do Ensino Superior (Sinaes), Lei n. 10.861/2004;

b) o Decreto n. 5.205/2004, que regulamenta as parcerias entre as universidades federais e as fundações de direito privado, viabilizando a captação de recursos privados para financiar as atividades acadêmicas;

c) a Lei de Inovação Tecnológica n. 10.973/2004, que trata do estabelecimento de parcerias entre universidades públicas e empresas;

d) o Projeto de Lei n. 3.627/2004, que institui o Sistema Especial de Reserva de Vagas;

e) os projetos de leis e decretos que tratam da reformulação da educação profissional e tecnológica;

f) o Projeto de Parceria Público-Privada (PPP), Lei n. 11.079/2004, que abrange um vasto conjunto de atividades governamentais;

g) o Programa Universidade para Todos (ProUni), Lei n. 11.096/2005, que trata de "generosa" ampliação de isenção fiscal para as instituições privadas de ensino superior;

h) o Projeto de Lei n. 7.200/2006, que trata da Reforma da Educação Superior e se encontra no Congresso Nacional;

i) a política de educação superior a distância, especialmente a partir da criação da Universidade Aberta do Brasil, Decretos n. 5.800/2006 e 5.622/2005;

j) o Programa de Apoio a Planos de Reestruturação e Expansão das Universidades Federais (Reuni), Decreto n. 6.096/2007, e o Banco de Professor-Equivalente;

k) o "pacote da autonomia", lançado em 2010 e composto pela Medida Provisória 495/2010 e pelos Decretos n. 7.232, 7.233 e 7.234/2010. Esse "pacote" amplia a ação das fundações 
de direito privado nas universidades federais; retira das universidades a definição dos projetos acadêmicos a serem financiados, transferindo essa prerrogativa para as fundações de direito privado; legaliza a quebra do regime de trabalho de Dedicação Exclusiva (DE); não resolve a falta de técnico-administrativos, criando somente um mecanismo de realocação de vagas entre as instituições federais de ensino superior (IFES); cria as condições para a diferenciação dos orçamentos das IFES, de acordo com índices de produtividade, intensificando ainda mais o trabalho docente e, por fim, cria o Programa Nacional de Assistência Estudantil (Pnaes), sem deixar claro de onde sairão os recursos financeiros para realização do Programa e

1) a Medida Provisória n. 520, de 31 de dezembro de 2010, que autoriza a criação da Empresa Brasileira de Serviços Hospitalares. Embora estatal e vinculada ao Ministério da Educação (MEC), a nova entidade terá personalidade jurídica de direito privado, flexibilizando a contratação de trabalhadores dos hospitais universitários.

Este vasto conjunto de ações pode ser agrupado em quatro nucleações básicas: 1) o fortalecimento do empresariamento da educação superior; 2) a implementação das parcerias público-privadas na educação superior; 3) a operacionalização dos contratos de gestão, eixos condutores da reforma neoliberal do Estado brasileiro, de Bresser-Cardoso a Paulo Bernardo-Lula da Silva e 4) a garantia a coesão social em torno das reformas estruturais realizadas pelos governos Cardoso e Lula da Silva.

O fortalecimento do empresariamento da educação superior ocorreu por diversas ações: pelo aumento do número de IES privadas e pela privatização interna das universidades públicas. Segundo informações, disponibilizadas no Censo 2002, ao final do governo Cardoso, o ingresso em IES públicas somava 320.354, enquanto nas IES privadas somava 1.090.854 (BRASIL, 2002). Caracterizando um acesso via diversificação das IES, direcionado especialmente às IES privadas não universitárias e que "não" precisam, por determinação legal, implementar políticas de pesquisa e extensão. Esta expansão via instituições privadas de ensino é identificada nos seguintes termos por Oliveira, Dourado e Amaral (2006, p. 16):

Dados do MEC/Inep/Seec, do Censo das Instituições de Ensino Superior de 2002, mostram que o sistema possui 1.637 instituições; dessas, 162 (9,9\%) são universidades, $77(4,7 \%)$ são centros universitários, 105 (6,4\%) são faculdades integradas, 1.240 $(75,7 \%)$ são faculdades, escolas e institutos e 53 $(3,2 \%)$ são centros de educação tecnológica.
Em relação ao segundo mecanismo (privatização interna das IES públicas), o governo Cardoso realizou um profundo reordenamento interno das universidades públicas, particularmente as federais. Esse processo ocorreu através de um arcabouço jurídico que permitiu: a venda de "serviços educacionais", como os cursos pagos, especialmente os cursos de pós-graduação lato sensu; o estabelecimento de parcerias entre as universidades federais e as empresas para realização de consultorias e assessorias viabilizadas pelas fundações de direito privado; a concepção de política de extensão universitária como venda de cursos de curta duração; a criação de mestrados profissionalizantes, em parcerias com empresas públicas e privadas, considerados como cursos autofinanciáveis, isto é, cursos pagos, entre outros mecanismos internos de privatização, analisados por vários pesquisadores (SGUISSARD; SILVAJR., 1999; SILVA JR., 2002; MANCEBO, 2004; LIMA, 2007).

Essa lógica não será alterada no governo Lula da Silva e a quantidade de leis, decretos e medidas provisórias comprova a prioridade em relação à reformulação da educação superior, conduzida, a partir de 2003, seja pela regulamentação das parcerias entre as universidades federais e as fundações de direito privado, seja pela possibilidade de cobrança de cursos e venda de "serviços educacionais" pelas IES públicas, seja pela Lei de Inovação Tecnológica, que viabiliza o trabalho docente nas empresas privadas e a ação destas empresas nas IES públicas, ou pelo aumento efetivo do número de IES privadas.

$\mathrm{O}$ estímulo à privatização da educação superior e das "instituições de ensino" (centros universitários e faculdades isoladas) não será, portanto, alterado no governo Lula da Silva, conforme demonstram os dados do Censo da Educação Superior de 2008. Se em 2002 (final do governo Cardoso) do total de 1.637 IES, 195 eram públicas e 1.442, privadas, em 2008, do total de 2.251 IES, 235 eram públicas e 2.016 eram IES privadas. Em relação à organização acadêmica, em 2002 o número de instituições estava assim distribuído: de 1.637 IES, 162 eram universidades, 77 centros universitários e 1.398 faculdades isoladas. Em 2008, de 2.252 IES, 183 eram universidades, 124 centros universitários e 1.945 eram faculdades isoladas (BRASIL, 2008). Ainda que apresentasse alterações em relação ao número de IES públicas, especialmente em relação às universidades, permaneceu a execução da política do BM: diversificação das IES e dos cursos e das suas fontes de financiamento.

A intensificação da privatização da educação superior é visível quando analisamos os dados referentes à criação dos Cursos de Graduação em Serviço Social (tabela 1) no primeiro governo Lula da Silva elencados nos estudos de Pereira (2007). 
Tabela 1 - Criação dos Cursos de Graduação em Serviço Social no Brasil

\begin{tabular}{|c|c|c|c|c|c|}
\hline Período & Privado & \% & Público & \% & Total \\
\hline $\mathbf{1 9 3 0 - 1 9 9 4}$ & 47 & 63,5 & 27 & 36,5 & 74 \\
\hline $\mathbf{1 9 9 5 - 2 0 0 2}$ & 44 & 89,8 & 05 & 10,2 & 49 \\
\hline $\mathbf{2 0 0 3 - 2 0 0 6}$ & 122 & 94,6 & 07 & 5,4 & 129 \\
\hline Total & 213 & 84,5 & 39 & 15,5 & 252 \\
\hline
\end{tabular}

Fonte: tabela elaborada pela autora, com base nos dados do INEP (BRASIL, 2007) e da pesquisa de Pereira (2007).

Tabela 2 - Cursos de Serviço Social distribuídos segundo natureza jurídica e organização acadêmica

\begin{tabular}{|c|c|c|c|c|}
\hline Organização acadêmica & IES públicas & \% & IES privadas & \% \\
\hline IES universitárias & 10 & 83,3 & 57 & 38,5 \\
\hline IES não universitárias & 02 & 16,7 & 91 & 61,5 \\
\hline Total & 12 & 100,0 & 148 & 100,0 \\
\hline
\end{tabular}

Fonte: tabela organizada por Pereira (2007).

Segundo Pereira (2007, p. 2), "até abril de 2008, existiam no Brasil 286 cursos de Serviço Social. Da totalidade dos cursos de Serviço Social existentes no país, $160(55,9 \%)$ foram autorizados a funcionar a partir do ano de 2003". Destaca que esta "explosão" de novos cursos "privados" em Serviço Social ocorreu, nesse período, em instituições não universitárias, restritas às atividades de ensino, conforme os dados da tabela 2.

Os estudos da autora demonstram que dos 160 Cursos de Serviço Social criados no referido período, 12 estão em IES públicas e 148 em IES privadas. Desses 148 Cursos em IES privadas, 57 estão em IES universitárias e 91 em IES não universitárias. Estes dados revelam que no período acima indicado foi mantida a política de ampliação do número de IES/ cursos privados e de estímulo a IES não universitárias que não precisam realizar pesquisa e são caracterizadas, em sua maioria, como "instituições de ensino".

A segunda nucleação temática trata da implementação das parcerias público-privadas (PPP) na educação superior. As PPP serão expressas através de várias ações realizadas pelo governo Lula da Silva, a contar da criação do ProUni, que garante isenção fiscal para o setor privado em troca de "vagas públicas" nas IES privadas ${ }^{7}$ até a Lei de Inovação Tecnológica, que viabiliza as parcerias entre as IES públicas e as empresas.

No mesmo sentido de mercantilização do conhecimento, em 2007, o MEC anunciou a Lei de Incentivo Fiscal à Pesquisa, Lei n. 11.487/2007 divulgada pela Capes (BRASIL, 2007, online) subordinando ainda mais a pesquisa e os programas de pós-graduação à concepção mercadológica da educação e do conhecimento:

\begin{abstract}
Com a Lei de Incentivo Fiscal à Pesquisa, as universidades enviarão projetos desenvolvidos em seus campi a uma comissão tripartite, formada pelos ministérios da Educação, Indústria e Comércio e Ciência e Tecnologia. Os projetos aprovados farão parte de um catálogo que será distribuído à iniciativa privada. As empresas que se interessarem por projetos do catálogo poderão doar entre $17 \%$ e $85 \%$ do valor do plano - e terão essa doação abatida de impostos (Imposto de Renda e Contribuição Social sobre o Lucro Líquido - CSLL). Essa porcentagem doada será convertida para a universidade em participação na propriedade intelectual do projeto, e o que faltar para $100 \%$ vai se tornar propriedade intelectual da empresa. Por exemplo: para um projeto aprovado pela comissão tripartite no valor de $\mathrm{R} \$ 100$ mil, uma empresa doa $\mathrm{R} \$ 75$ mil, $75 \%$ da patente será da universidade que gerou o projeto, e os outros $25 \%$ da propriedade intelectual serão da empresa que doou os recursos.
\end{abstract}

A terceira nucleação temática trata da operacionalização dos contratos de gestão, eixos condutores da reforma neoliberal do Estado brasileiro, de Bresser-Cardoso a Paulo Bernardo-Lula da Silva. Uma referência importante e atual desta operacionalização é o Programa de Apoio a Planos de Reestruturação e Expansão das Universidades Federais (Reuni). O Reuni foi apresentado através de Decreto presidencial n. 6.096/2007 e tem como objetivos: aumentar o número de estudantes de graduação nas universidades federais; aumentar o número de alunos por professor em cada sala de aula da graduação; diversificar as modalidades dos cursos de graduação, 
através da flexibilização dos currículos, da educação a distância, da criação dos cursos de curta duração e dos ciclos (básico e profissional); incentivar a criação de um novo sistema de títulos; elevar a taxa de conclusão dos cursos de graduação para 90\% e estimular a mobilidade estudantil entre as instituições de ensino. Tudo isto no prazo de cinco anos.

Para cada universidade federal que aderir a este "termo de pactuação de metas", ou seja, um contrato de gestão com o MEC, o governo "promete" um acréscimo de recursos limitado a vinte por cento das despesas de custeio e pessoal. Entretanto, uma análise cuidadosa do parágrafo terceiro do artigo $3^{\circ} \mathrm{e}$ do artigo $7^{\circ}$ do Decreto de criação do Reuni deixa claro em que termos ocorrerá esta "expansão", pois “o atendimento aos planos é condicionado à capacidade orçamentária e operacional do MEC" e "as despesas decorrentes deste processo devem estar circunscritas às dotações orçamentárias consignadas anualmente ao MEC".

A análise do Reuni evidencia de que forma e com que conteúdo está ocorrendo a expansão do acesso à educação superior. Trata-se do tripé: aligeiramento da formação profissional (cursos de curta duração, ciclos, exame de proficiência, cursos a distância); aprofundamento da intensificação do trabalho docente (relação professor/aluno, ênfase das atividades acadêmicas no ensino de graduação) e pavimentação do caminho para transformação das universidades federais em "instituições de ensino terciário", quebrando a indissociabilidade entre ensino, pesquisa e extensão e decretando, efetivamente, o fim da autonomia universitária, na medida em que a alocação das verbas públicas está condicionada à adesão ao contrato de gestão/Reuni (LIMA, 2008).

A reestruturação e expansão operada pelo Reuni resulta, assim, na intensificação do trabalho docente em sua dupla face na graduação: o aumento do número de alunos em cada sala, somado ao aumento do número de cursos e da relação professor/aluno, está conformando a figura do "professor do ensino terciário", aquele que - pela quantidade de trabalho na graduação - não desenvolve ou desenvolve com muitas limitações um projeto de pesquisa e/ou extensão; um professor que não publica ou publica "pouco" (segundo as exigências da Capes e do CNPq), pois não tem tempo para escrever; que não participa de eventos científicos nacionais e/ou internacionais porque não tem verba pública disponibilizada para garantir esta participação. É um processo difícil de ser rompido: o professor não é considerado "produtivo" porque está alocado na graduação, não atua em programas de pós-graduação, não pesquisa e não publica. Ao mesmo tempo, ele não consegue sair do papel de "professor do ensino terciário" na medida em que é avaliado como "improdutivo" pelos órgãos superiores das universidades (pró-reitorias) e/ou pelos órgãos de fomento ${ }^{8}$ (LIMA, 2010).
A quarta nucleação temática expressa o objetivo das reformas e políticas da educação superior em curso no Brasil: a garantia da coesão social em torno das reformas estruturais (previdênciária, tributária, sindical e trabalhista), realizadas pelo governo Lula da Silva em absoluta consonância com as políticas dos organismos internacionais do capital. Nesse sentido, a desconstrução da educação superior pública brasileira é apresentada como "democratização" do acesso à educação para os segmentos mais pauperizados da população. O ProUni, o Fundo de Financiamento ao Estudante do Ensino Superior (FIES), o ensino a distância, o projeto Escola na Fábrica, as "universidades" tecnológicas, os cursos sequenciais, os cursos de curta duração e o Reuni constituem importantes referências da política de ampliação de acesso à educação utilizada pelo Governo Federal para legitimar suas ações por intermédio de uma eficiente operação ideológica que as reveste de um ilusório verniz democrático-popular.

\section{A título de consideração final}

A análise dos documentos do BM e das políticas executadas pelos governos Cardoso e Lula da Silva demonstra que está em curso um intenso processo de reforma neoliberal do Estado e da educação superior no Brasil. Não se trata de uma "imposição" dos organismos internacionais ou da subordinação do Brasil às determinações vindas "de fora", ainda que o mecanismo das condicionalidades esteja presente nos acordos firmados entre os governos brasileiros e o BM, mas de um "compartilhamento" da concepção de educação como "ensino terciário".

O que se evidencia, na primeira década do século 21, é a estruturação de um tipo de universidade adequada à atual etapa de acumulação do capital, particularmente em um país capitalista dependente como o Brasil. Uma estruturação que transita da privatização direta, passando pelo novo modelo de gestão, introduzido pelo padrão gerencial e coroado com a quebra de indissociabilidade entre ensino, pesquisa e extensão e a mercantilização do conhecimento. Um processo que configurou a educação superior como um campo de exploração lucrativa para o capital em crise e aprofundou sua função política, econômica e ideo-cultural de reprodução da concepção burguesa de mundo.

\section{Referências}

BANCO MUNDIAL. La enseñanza superior - Las lecciones derivadas de la experiencia. Washington, 1994. Disponível em: <http://www.bancomundial.org.br $>$. Acesso em: 9 abr. 2010. 
Relatório sobre o desenvolvimento mundial. O Estado em um mundo em transformação. 1997. Disponível em: <http://www.bancomundial.org.br/index.php/content/ view folder/94.html >. Acesso em: 12 abr. 2010.

Documento estratégico do Banco Mundial. A educação na América Latina e Caribe. 1999. Disponível em: <http://www.bancomundial.org.br>. Acesso em: 8 abr. 2010.

Construir sociedades de conocimiento: nuevos desafíos para la educación terciaria. 2002. Disponível em: <http://siteresources.worldbank.org/EDUCATION/ Resources/278200-1099079877269/547664-

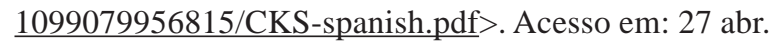
2010.

BRASIL. Capes - Coordenação de Aperfeiçoamento de Pessoal de Nível Superior. Haddad apresenta parcerias público-privadas para delegação americana. 2007. Disponível em: <http://www.capes.gov.br/servicos/ salaimprensa/noticias/noticia 0763.html $>$. Acesso em: 12 abr. 2009.

. INEP - Instituto Nacional de Estudos e Pesquisas Educacionais. Censo da Educação Superior Brasileira. Resumo Técnico, 2002. Disponível em: 〈http:// www.inep.gov.br/download/superior/censo/ tabelas resumo tec .xls>. Acesso em: 15 dez. 2009.

. INEP - Instituto Nacional de Estudos e Pesquisas Educacionais . Censo da Educação Superior. 2008. Disponível em: <http://www.inep.gov.br/download/censo/ 2008/resumo tecnico 20081512 09.pdf >. Acesso $6 \mathrm{em}$ : abr. 2010.

CHESNAIS, F. Mundialização financeira e vulnerabilidade sistêmica. In: (Coord.) A mundialização financeira: gênese, custos e riscos. São Paulo: Xamã, 1999.

LIMA, K. Contrarreforma na educação superior: de FHC a Lula. São Paulo: Xamã, 2007.

. Reuni e banco de professor equivalente: novas ofensivas da contrarreforma da educação superior brasileira no governo Lula da Silva. Revista Universidade e Sociedade, Brasília: ANDES/SN, n. 41, p. 69-78, 2008.

. O novo rosto da educação superior pública. $R e$ vista Classe, Aduff/Seção Sindical, ano 2, n. 3, p. 18-24, 2010.

MANCEBO, D. Reforma universitária: reflexões sobre a privatização e a mercantilização do conhecimento. 2004. Disponível em: <http://www.scielo.br/pdf/es/v25n88/ a10v2588.pdf>. Acesso em: 4 maio 2009.
Universidade para todos: a privatização em questão. 2004a. Disponível em: <http://www.anped.org.br/ reformauniversitaria4.doc >. Acesso em: 12 mar. 2010.

NEVES, L. (Org.). O empresariamento da educação. Novos contornos do ensino superior no Brasil dos anos 1990. São Paulo: Xamã, 2002.

OLIVEIRA, J. F; DOURADO, L. F; AMARAL, N. C. Desafios e perspectivas de uma política para as Instituições Federais de Ensino Superior (IFES). Brasília: MEC/INEP, 2006, p. 9-49. (Série Documental, v. 23).

PEREIRA, L. D. Mercantilização do ensino superior e formação profissional em Serviço Social: uma análise da direção social e das condições de formação profissional dos assistentes sociais brasileiros. Niterói: ESS/UFF, 2007. (Projeto de Pesquisa).

ROSA, R. N. Ensino superior em crise. 2007. Disponível em: <http://pararbolonha.blogspot.com/2007/02/o-ensinosuperior-em-crise-por-rui.html $>$. Acesso em: 21 abr. 2010.

SGUISSARD, V.; SILVA JR, J. dos R. Novas faces da educação superior no Brasil. Reforma do Estado e mudança na produção. Bragança Paulista: Edusf, 1999.

Trabalho intensificado nas federais. Pósgraduação e produtivismo acadêmico. São Paulo: Xamã, 2009.

SILVA JR., J. dos R. Reforma do Estado e da educação no Brasil de FHC. São Paulo: Xamã, 2002.

UGÁ, V. D. A questão social como pobreza: crítica à conceituação neoliberal. 232 p. Tese (Doutorado em Ciência Política) - Instituto Universitário de Pesquisas do Rio de Janeiro, 2008.

\section{Notas}

1 Uma análise cuidadosa dos documentos do BM demonstra que suas políticas não tratam da "educação" (ainda que este seja o termo utilizado), mas de um "ensino" massificado, concebido como transmissão de informações, treinamento, instrução e capacitação, absolutamente desarticulado da pesquisa e da produção do conhecimento crítico e referenciado nas lutas históricas da classe trabalhadora.

2 Utilizaremos neste artigo o conceito de países periféricos como contraposição à noção de "países em desenvolvimento" utilizada pelo BM, porconsiderarmos essa noção uma das importantes estratégias de ocultamento de um dos elementos constitutivos do capitalismo: a lei desigual do desenvolvimento da economia mundial. 
3 Para aprofundar a análise crítica sobre o uso da categoria pobreza nas políticas do BM, consultar Ugá(2008).

4 Vale conferir a condução deste processo através do Acordo de Bolonha. Indico especialmente os textos de Rosa (2007) sobre o significado político e pedagógico deste "Acordo".

5 Para aprofundar a análise crítica da noção "sociedade da informação/conhecimento”, consultar Lima(2007).

6 Todos esses documentos relacionados, e os demais indicados ao longo do texto (leis, decretos e medidas provisórias) estão disponíveis em: <http://www. planalto.gov.br/legislação’.

7 Uma interessante análise sobre o significado do ProUni é desenvolvida em Mancebo(2004a).

8 A outra face desta intensificação do trabalho docente ocorre pelo "produtivismo acadêmico": professores que além de atuarem na graduação, atuam nos programas de pósgraduação e têm "metas de produção" a serem atingidas, como o número de livros, capítulos de livros, artigos, participação em eventos nacionais e internacionais. O Reuni opera a primeira face da intensificação acima indicada e as políticas de pesquisa e pós-graduação operam a outra face desta intensificação do trabalho docente. Uma importante análise crítica da intensificação do trabalho docente, implementada pelas políticas de pós-graduação e pesquisa é realizada por Sguissard e Silva Jr. (2009).

\section{Kátia Regina de Souza Lima}

katiaslima@globo.com

Doutorado em Educação pela Universidade Federal

Fluminense (UFF)

Professora adjunta da Escola de Serviço Social e do Programa de Pós-Graduação em Educação da UFF

UFF - Escola de Serviço Social e Programa de Pós-Graduação em Educação

Campus do Gragoatá s/n

Blocos E $5^{\circ}$ andar

Bairro São Domingos

Niterói - Rio de Janeiro

CEP: 24210-350 